\title{
Puesta en escena objetual e interactiva
} Objectual and Interactive Staging

Ana María Alvarado ${ }^{1}$ 


\section{Resumen}

La reflexión sobre la relación entre cuerpo y objeto en la escena en la era de la virtualidad dio origen en la Universidad Nacional de las Artes, en Argentina a la carrera de posgrado Especialización en Teatro de Objetos, interactividad y Nuevos Medios y a la investigación que llamamos Cosidad, carnalidad y virtualidad. Cuerpos y objetos en la escena, editada en formato de libro físico en el 2018, con el apoyo de esa misma universidad. Este artículo retoma y amplía algunas de los conceptos de ese proyecto, los que muestran más claramente el recorrido que se inicia en los títeres y continúa en el teatro objetual $y$ visual. Reflexiona también sobre las nociones de cuerpo real y cuerpo virtual, las similitudes y diferencias de lo que llamamos animación e interacción $y$, por último, su presencia en la escena compleja y expandida.

Palabras claves: Teatro de Objetos; Teatro visual; interactivo; vivo o mediatizado

\section{Abstract}

The reflection on the relationship between body and object on the scene at the virtuality era gave origin to the postgraduate course in Object theatre, Interactivity and New Media at the National University of Arts, and also to the investigation called Thingness, Carnality and Virtuality. Bodies and Objects in the Scene, edited in a physical book in 2018 with the National University of Arts endorsement. This article takes up and extends concepts of that project, those that clearly show the path that initiate with the puppetries and continues in the Visual and Object Theatre. It also reflects on the notions of real body and virtual body, the similarities and differences of what we call animation and interaction, and finally, their presence in the complex and expanded scene.

Keywords: Object Theatre; Visual theater; interactive; live or mediated 
Existe actualmente en la Ciudad de Buenos Aires, una opción para que los interesados en el campo de los títeres y objetos puedan formarse dentro de una universidad en un programa de posgrado: la Especialización en Teatro de Objetos, Interactividad y Nuevos Medios de la Universidad Nacional de las Artes.

Esta última fue creada en 2011 y se propone que el Teatro de Objetos coteje su tradición interdisciplinar encontrándose con las nuevas tecnologías. El cuerpo docente y directivo de la carrera considera que los manipuladores y animadores de teatro objetual tienen una gran capacidad de adaptación al uso creativo de las nuevas tecnologías interactivas y pueden ser un vehículo importante para que el teatro en general se encuentre con los nuevos medios y genere respuestas creativas a las preguntas frecuentes sobre el mejor modo de integrar los nuevos medios a la escena teatral.

La carrera tiene el carácter de especialización y, en ese sentido, busca que el saber teórico vaya ligado a la práctica. Nuestros estudiantes ejercitan la interpretación con objetos, la dramaturgia para ese tipo de teatro y estudian el devenir de las artes hibridadas desde principios del siglo XX hasta la actualidad. Sumado a estos contenidos, habituales en otras carreras, se realizan actividades que otorgan conocimientos básicos de electrónica, crean objetos híbridos, trabajan con programas que les permiten generar sistemas interactivos de bajo costo y con tecnologías accesibles. Todo esto los libera de la absurda mirada sumisa y tecno-dependiente típica de nuestra cultura. Los vuelve autónomos. La universidad tiene como una de sus funciones principales apoyar a los estudiantes en su autonomía intelectual y, en nuestro caso, favorecer el desarrollo de artistas independientes.

Los estudiantes de esta carrera son oriundos de distintos países de Latinoamérica y Europa y tienen formaciones diversas. Algunos son titiriteros, otros actores, directores, artistas visuales, performers, críticos, músicos y artistas multimediales. Todos nos dejan al graduarse una nueva mirada sobre el objeto en las artes y una consistente esperanza en el destino de la interdisciplinariedad.

La carrera estuvo asociada hasta el año 2017 a un proyecto de investigación inserto en la Universidad Nacional de las Artes al que llamamos Cosidad y Carnalidad: Objeto autónomo y sujeto intermediario.

En la fundamentación de este proyecto dijimos:

Buscamos establecer que existe una obra artística en el país que expresa la relación objeto -cuerpo físico y cuerpo virtual, en un modo nuevo y que se presenta en el circuito que la recibe: teatros, museos, fundaciones, sin sentirse definitivamente parte de ninguno, pudiendo fluctuar de una expresión a otra, sin buscar ser conclusiva, muy cercana al cuerpo del propio artista y vinculada con lo objetual en modos diversos ${ }^{2}$.

El enfrentamiento o no del cuerpo (humano) y la cosa (objeto) en las artes escénicas dio origen al encuentro entre los investigadores que trabajaron en este proyecto citado anteriormente. La carrera creada produjo nuevas reflexiones sobre el concepto de objeto en la era de la virtualidad y el rol del interactor en la tecnoescena. Algunas

${ }^{2}$ Alvarado, 2018, p. 7 
de esas reflexiones se plasmaron en el libro Cosidad, Carnalidad y Virtualidad, editado este año, con el apoyo de la UNA. Este artículo visita algunas de los conceptos que desarrollamos en ese libro.

Las imágenes, los cuerpos y los objetos construyen una nueva escena objetual y buscan definir su nuevo emplazamiento. ¿Qué hace el objeto cuando participa en obras donde la separación entre interioridad y exterioridad está rota? El paradigma del objeto escénico y el espacio-tiempo asociado, han sido alterados, hay que buscar nuevos espacios, nuevos emplazamientos, "sitios" de orden físico o virtual.

En el teatro objetual, los objetos artísticos o en función artística, mantuvieron durante mucho tiempo una relación de dependencia recíproca con el actor manipulador pero esa intensidad está actualmente en cuestión. En principio, la escena teatral se puebla de "cosas" que pueden ser manipuladas o no en escena y de cuerpos humanos reales o virtuales. Una batalla escénica entre la carne y la cosa. Cuerpos reales manipulando objetos físicos. Cuerpos interactivos conectados a dispositivos informáticos. Cuerpos y objetos virtuales. Las posibilidades son muchas.

El maridaje entre tecnología y teatro puede tener un final feliz siempre y cuando el espectáculo teatral asuma el encuentro como parte de su partitura. Ese es siempre el secreto. Un texto escénico que contemple desde el inicio la posiblidad del uso de la tecnología digital. Las escenografias digitales, por ejemplo, cuando son bellas pero no imprescindibles, producen una sensación de saturación que la puesta en escena, muchas veces rechaza. La tecnología digital es una herramienta y un reservorio de información valiosa para el teatro pero su empleo debe ser de necesidad inexorable para la partitura escénica.

La partitura es un trabajo diferente a la dramaturgia y a la dirección e implica un director que privilegia la puesta en escena. Así podríamos considerar a Appia, a Craig, a Piscator, a Wilson y a tantos otros mucho más actuales que basaron su trabajo en la noción de partitura. La forma escénica era determinante de la forma dramática para Piscator y la partitura se escribía entre el director, el autor y el escenógrafo, probablemente en ese orden. De sus nociones de montaje y simultaneidad, el teatro actual es más que deudor. Max Reinhardt también creaba bajo el concepto de partitura.

Los efectos son en muchos casos más importantes que las palabras. Lo primero es obtener una visión global del drama, que progresivamente se va concretando hasta alcanzar el detalle de cada gesto, cada paso, cada mueble, cada sonido. Entonces es cuando esas visiones acústicas y sonoras, perfectamente configuradas, se inscriben como una partitura 3 .

El teatro de objetos ha tenido desde sus orígenes la necesidad de un montaje de campos en el que el texto dramático no sea lo más relevante.

Hoy en nuestro apabullante mundo tecnologizado, los objetos, igual que los organismos, están en crisis. Podría decirse que nuestro mundo actual es un mundo post-objetual. A pasos agigantados la multiplicidad de objetos que usábamos para nuestro trabajo, confort, comunicación y entretenimiento se reducen hasta convertirse en un muy pequeño objeto que nos provee todo y cuyo diseño es extremadamente minimal. Los demás están convirtiéndose en un depósito de melancolía. La

3 Sanchez, 2002, p. 41 
proyección del desarrollo tecnológico y las perspectivas hacia el futuro en materia de innovación aumentarían este tipo de interacciones aún más. Los objetos interactivos nos están condicionando, y modifican todas las operaciones con nuestro entorno, aun cuando dichas interacciones no sean de naturaleza digital. Las relaciones entre sujetos y objetos son consecuentemente actualizadas mediante la interactividad, afectando nuestro percibir, nuestro entorno y desenvolvimiento en él, influyendo también transversalmente en las interacciones de todos los campos.

Para los que trabajamos con objetos estos desechos son un basurero poético altamente necesario para la creación escénica, pero como queremos continuar activos y actualizados, miramos al pequeño tirano también como un arma creativa y lo sometemos a la meta-ironía duchampiana para que pueda autocriticarse.

La tecno-escena puede ocurrir sin un escenario, con un concepto de espaciotiempo absolutamente desplazado hacia la calle, la galería, la pantalla, pero además puede estar "in presencia" física a través exclusivamente de su imagen, sin objeto y sin actor. El manipulador puede ser un interactor o incluso el público puede ser el autor e interactor.

El interactor entra al espacio de una pieza y su gestual (mano, mirada, movimiento) activa la obra. El arte interactivo es una práctica artística no contemplativa, es una performance, una ocupación que mantiene a todo el mundo atareado: artistas y espectadores. Se sugiere que la obra funciona dentro de lo que Baudrillard llama gestual de control:

Este gestual mínimo es en cierta manera necesario: sin él toda esta abstracción de poderío perdería su sentido. Es necesario que una participación, por lo menos formal, le asegure al hombre su poderío 4 .

En su libro el autor hace un elaborado desarrollo de las concepciones del universo material, la imposición del hombre, el conocimiento humano sobre la materia que le permite forzarla y crear objetos con diversas funciones, incluidas las estéticas y con la obsolescencia prevista.

Las interacciones están medidas actualmente por interfaces digitales. Una dimensión ampliada del concepto de objeto hacia un recurso modular codificable que pueda ser tanto material como inmaterial podría considerar al código como el elemento fundamental de desarrollo de los nuevos objetos/artefactos implicando una actualización en la interacción entre objeto y sujeto. "Desde la internet de las

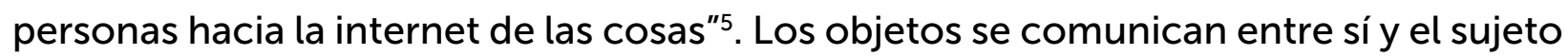
opera como usuario o mero intermediario. Cuando no opera como usuario, el sujeto de la innovación crea y opera colaborativamente para generar los objetos/artefactos de sistemas modulares. El objeto artístico se despliega hacia otras dimensiones intangibles o virtuales.

En gran medida los artistas que pensamos y creamos en el campo del teatro objetual y la escena performática o instalativa, consideramos al espacio escénico como un ambiente funcional en el que se ofrecen infinitas posibilidades de sentido y para el que hay que confeccionar partituras específicas.

${ }^{4}$ Baudrillard, 1985, p. 54

${ }^{5}$ Palermo, 2018, p.190 


\section{Referências}

ALVARADO, Ana, compiladora. Cosidad,carnalidad y virtualidad. Cuerpos y objetos en la escena. Buenos Aires: UNA, 2018.

BAUDRILLARD, Jean. El sistema de los objetos. Siglo XXI Editores. México, 1985.

PALERMO, Agustina. Cosidad, carnalidad y virtualidad. Actualización entre sujeto y objeto en la innovación. Buenos Aires: UNA, 2018.

SANCHEZ, José. Dramaturgias de la Imagen. Colección Monografías-Ediciones. Universidad de Castilla. España, 2002.

Recibido en: $15 / 07 / 2018$

Aprobado en:19/07/2018

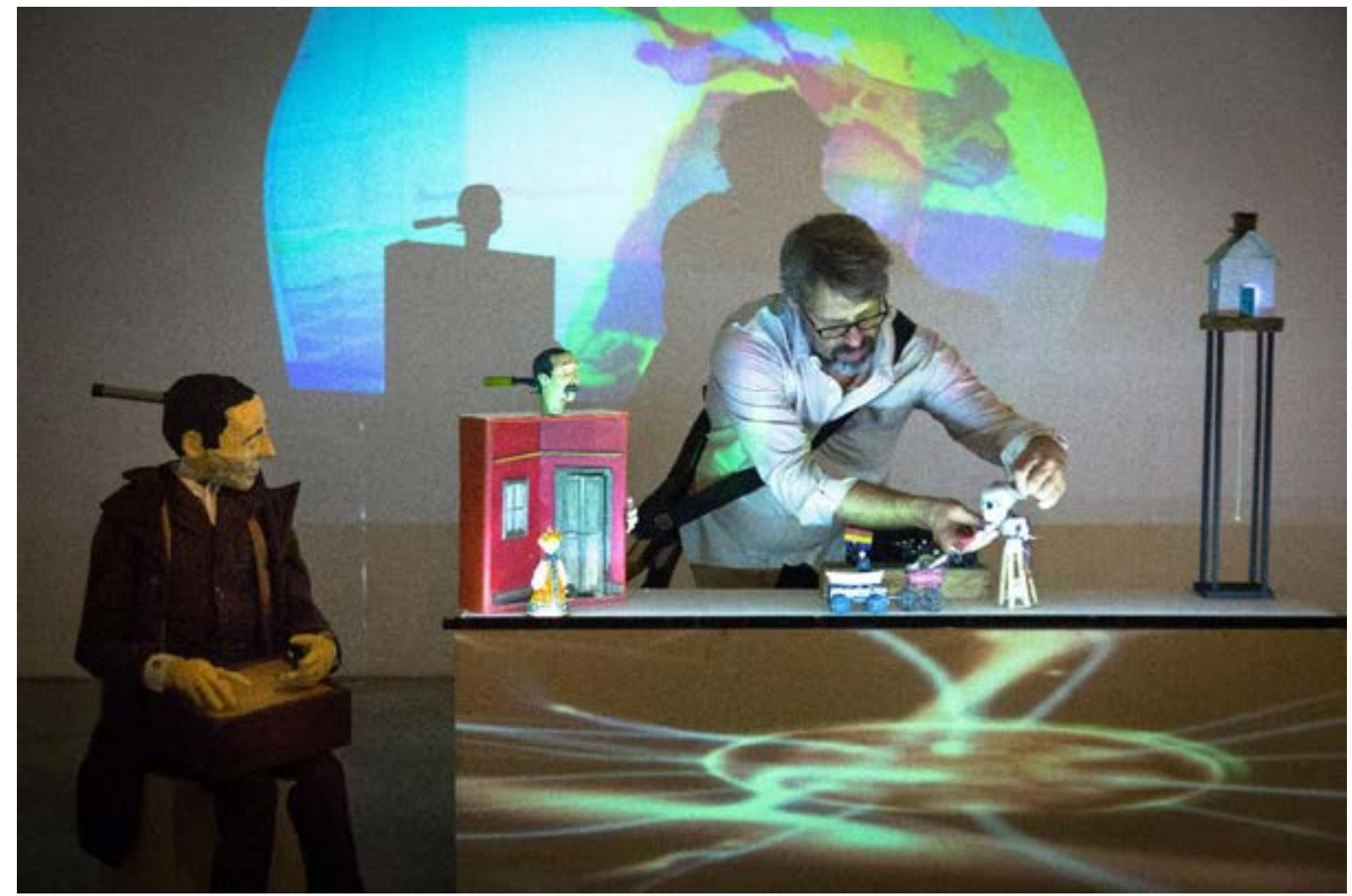

Performance: Diarios de 15 - Foto: Julieta Jons 


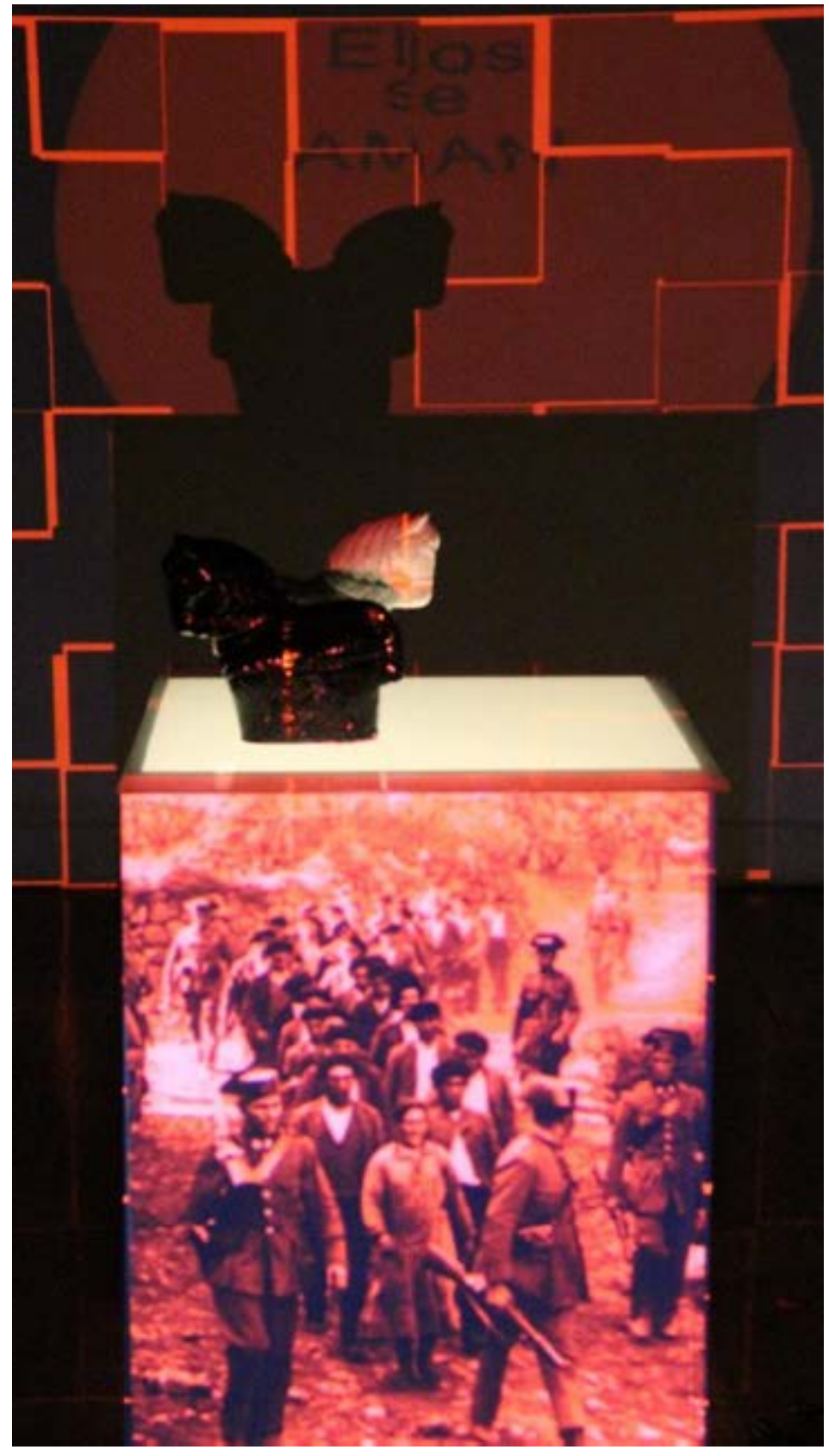

Performance: Encuentro con el público. Foto: Alejandra D’agostino 


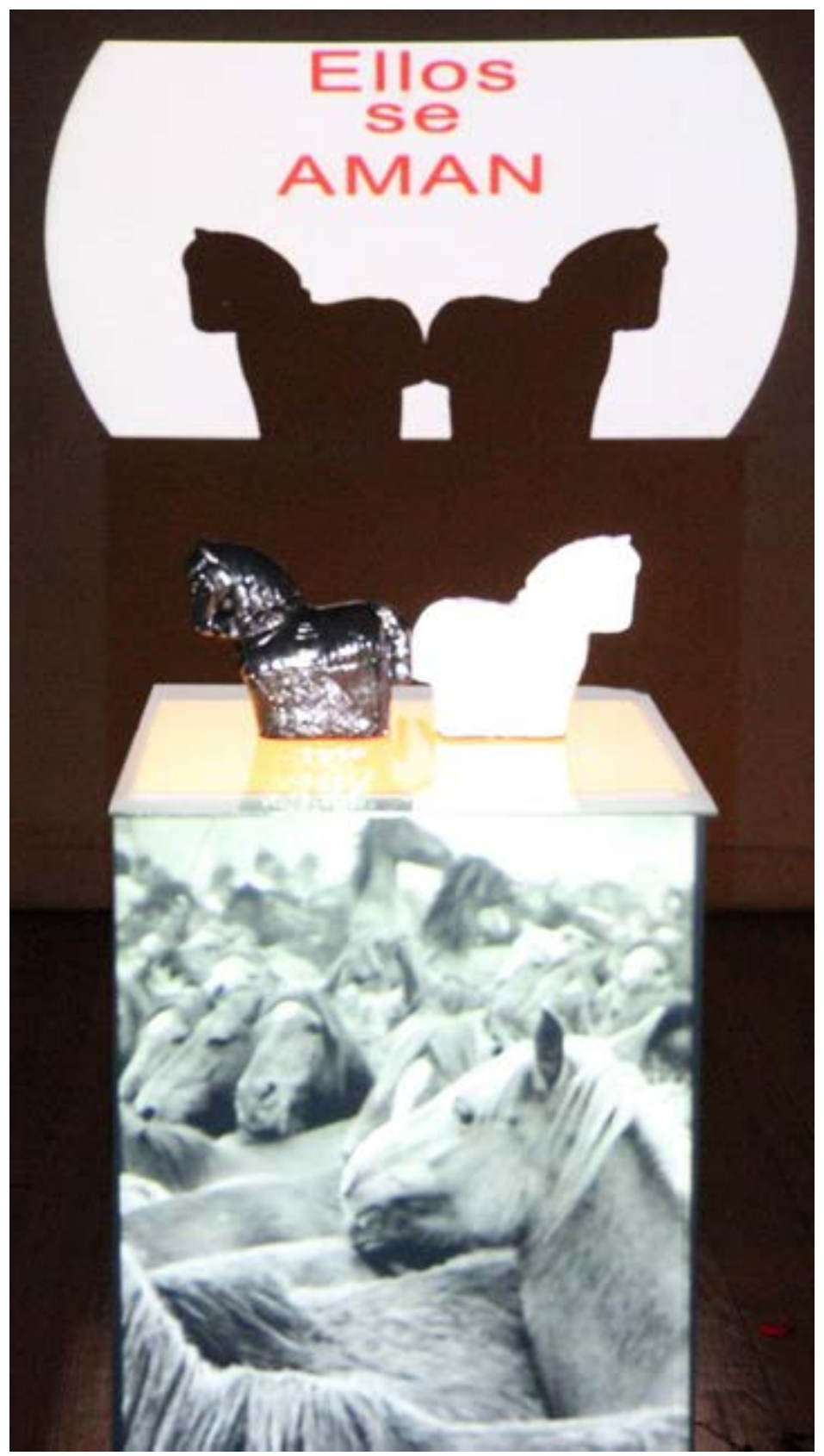

Performance: Encuentro con el público. Foto: Alejandra D’agostino 